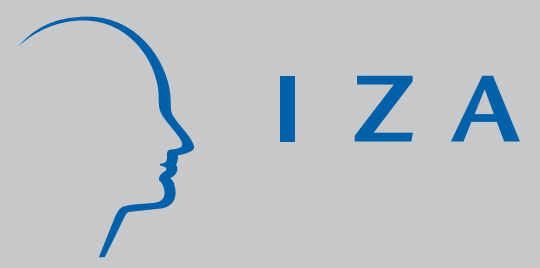

IZA DP No. 1300

Estimating the Threat Effect of Active Labour Market Programmes

Michael Rosholm

Michael Svarer

September 2004 


\title{
Estimating the Threat Effect of Active Labour Market Programmes
}

\author{
Michael Rosholm \\ University of Aarhus \\ and IZA Bonn \\ Michael Svarer \\ University of Aarhus
}

\section{Discussion Paper No. 1300 \\ September 2004}

\author{
IZA \\ P.O. Box 7240 \\ 53072 Bonn \\ Germany \\ Phone: +49-228-3894-0 \\ Fax: +49-228-3894-180 \\ Email: iza@iza.org
}

Any opinions expressed here are those of the author(s) and not those of the institute. Research disseminated by IZA may include views on policy, but the institute itself takes no institutional policy positions.

The Institute for the Study of Labor (IZA) in Bonn is a local and virtual international research center and a place of communication between science, politics and business. IZA is an independent nonprofit company supported by Deutsche Post World Net. The center is associated with the University of Bonn and offers a stimulating research environment through its research networks, research support, and visitors and doctoral programs. IZA engages in (i) original and internationally competitive research in all fields of labor economics, (ii) development of policy concepts, and (iii) dissemination of research results and concepts to the interested public.

IZA Discussion Papers often represent preliminary work and are circulated to encourage discussion. Citation of such a paper should account for its provisional character. A revised version may be available directly from the author. 


\section{ABSTRACT \\ Estimating the Threat Effect of Active Labour Market Programmes*}

We combine two techniques to consistently estimate the effect of active labour market programmes and, in particular, active labour market policy regimes. Our aim is to explicitly estimate the threat effect of active labour market programmes. Based on Danish data (19982002) from administrative registers we find a strong and significantly positive threat effect. The threat effect is shown to reduce average unemployment duration by approximately three weeks. The implications of this result are discussed.

JEL Classification: $\quad$ C41, J64

Keywords: active labour market policy, threat effect, timing-of-events, duration model

Corresponding author:

Michael Rosholm

Department of Economics

University of Aarhus

Building 326

8000 Aarhus C

Denmark

Email: mrosholm@econ.au.dk

\footnotetext{
* We thank seminar participants at AKF, University of Aarhus, University of Copenhagen, at the Survival of the Fittest conference in Bielefeld, 2004, and at the Nordic Labour Market Policy conference in Copenhagen, 2004, for useful comments. We are grateful to Annette B. Andersen for reading the manuscript and to Bo Hammer and Klaus Langager from the Danish National Labour Market Authority for access to the data used in the paper. Michael Svarer thanks the Danish National Research Foundation for support through its grant to CAM. Michael Rosholm thanks the Danish Ministry of Social affairs for financial support through the Danish Graduate School for Integration, Production and Welfare.
} 


\section{Introduction}

The use of active labour market programmes is often motivated by the need to upgrade the skills of long-term unemployed in order to improve their employability. There is now ample evidence that in terms of increasing job finding rates for long-term unemployed, active labour market programmes (henceforth ALMPs) have small and in some cases even adverse effects (see e.g. Heckman et al., 1999). Calmfors et al. (2001) confirm these findings in a Swedish study, and they argue that the extent of ALMPs in Sweden has been taken too far to be cost effective. Like Sweden, Denmark has very extensive and expensive ALMPs, ${ }^{1}$ and in both countries participation is mandatory after a (fairly short) period in open unemployment. Yet, faced with these allegations, policy makers often make the claim that ALMPs are valuable as a test of the (long-term) unemployed's availability for work. Moreover, they claim that the threat of programme participation is so harsh that some individuals increase their search activity and/or lower their reservation wages in order to find a job before the programme starts.

In this paper we propose a method to identify and estimate the threat effect of ALMPs. We also estimate the effects of actual programme participation on the job finding rate of unemployed individuals, and we can thus calculate the net impacts of active labour market policy regimes.

We follow a recent tradition in the programme evaluation literature and use hazard models to investigate this issue (see e.g. Gritz, 1993; Bonnal et al., 1997; Richardson \& van den Berg, 2001; and Lalive et al., 2001). In this literature, the effects of ALMPs on job finding rates are typically decomposed in two separate effects; a locking-in effect and a post-programme effect. The locking-in effects refer to the period a person participates in a programme. During this period, job search intensity may be lowered, because there is less time to search for a job, and also because the individual might want to complete an ongoing skill-enhancing activity. Ex ante it is therefore predicted that the job finding

\footnotetext{
${ }^{1}$ According to Martin \& Grubb (2001) more than 1.5\% of GDP is spent on ALMPs in Denmark, which ranks Denmark on top of OECD countries together with Ireland and The Netherlands. The unweighted OECD average is $0.8 \%$ of GDP, and in the U.S. it is only $0.15 \%$.
} 
rate is lower during participation in a programme, hence the name locking-in effect. The post-programme effect refers to the period after participation in a programme. If the ALMP has increased the individual's employability, an increase in the job finding rate is to be expected. The combination of these two effects consequently determines the net effects of ALMPs on unemployment duration, and as mentioned above they are typically small, insignificant, or both.

There might, however, be more to the story; for example a very important threat effect of ALMPs that affects the behaviour of unemployed individuals before they become enrolled in ALMPs. For some unemployed, participation in ALMPs might not be very attractive, perhaps because it is stigmatizing, it is like a tax on leisure time (you receive your unemployment benefits, but you have to turn up at "work" each day), and the payoffs are clearly not very promising. It is therefore argued that to avoid participation unemployed will increase their job search effort and lower their reservation wages, and as a consequence they will leave unemployment faster when faced with a threat of programme participation than without the threat.

In addition to estimating the threat effect of ALMPs, we show that neglecting the threat effect may cause a downward bias in the estimated locking-in and postprogramme effects and thereby lead to underestimation of the true effect of ALMPs on job finding rates.

The argument is that the counterfactual situation is altered when the threat effect is taken into account. If the threat effect is not separately estimated, it will be embedded in the estimates of the baseline hazard rate out of unemployment. Consequently, locking-in and post-programme effects are measured relative to a counterfactual situation where the individual does not participate in ALMPs, but is unemployed in a country with an active labour market policy regime, that is, where the implicit threat of programme participation is present simply because participation becomes mandatory after a period in open unemployment. When the presence of the threat effect is accounted for, the counterfactual situation is a passive labour market policy regime, that is there are no ALMPs. 
Figure 1 illustrates the argument made above. If a positive threat effect exists, but is ignored in the estimations, we will compare participants' outcomes to a counterfactual situation illustrated by the fat line. If the relevant counterfactual is a system without ALMPs, the relevant comparison is the hazard rate represented by the thin solid line, where the threat effect has been 'cleansed out'. Ignoring a positive threat effect will tend to give a negative assessment of ALMPs, since the locking-in effect will be too large ('too' negative), and the post-programme effect will be too small. Moreover, observe that the difference between the two solid lines (until the participaton period) is the threat effect; it illustrates how the presence of the ALMPs affects the exit rate out of unemployment of those who do not (yet) participate in ALMPs.

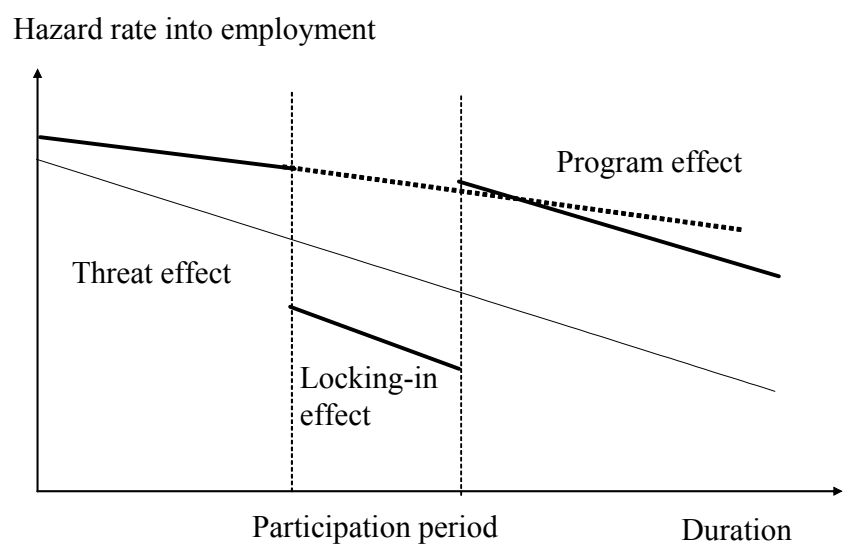

Figure 1: The effects of ALMPs on the hazard rate out of unemployment.

In order to estimate the threat effect and the total effect of ALMPs on job finding rates we propose a method that combines the timing-of-events model of Abbring \& van den Berg (2003) with a model for detecting dependencies in competing risks models (Lillard, 1993; Rosholm \& Svarer, 2001). 
The timing-of-events model (in this application) simultaneously models the transition rate out of unemployment and the transition rate into ALMPs, thus taking into account selection on observed and unobserved variables. Abbring \& van den Berg (2003) show that with an assumption of 1) mixed proportional hazards and 2) a non-defective distribution of time until participation in ALMPs given observed explanatory variables, the effects of participation in ALMPs are identified non-parametrically. The implication is that there is no need for an exclusion restriction, that is, a variable which appears in the selection equation, but which does not affect the outcome variable, in this case the hazard rate out of unemployment. The intuition is that random variation in the timing of the event participation in ALMP separates the treatment effect from the distribution of unobserved heterogeneity, which is assumed to be time-invariant.

The 'dependent hazard rates' model simultaneously models two hazard rates, but allows one of them to depend on the other. For example, the divorce rate may depend on the couple-specific fertility rate, or the hazard rate from unemployment into a new job may depend on the recall hazard if unemployed workers expecting a recall search less for new jobs (see e.g. Rosholm \& Svarer, 2001).

When we combine these two approaches, it is possible to estimate both the threat effect of ALMPs as well as the locking-in and post-programme effects, while taking into account the endogeneity of participation in ALMPs. The idea is that anticipation of participation in ALMP may affect the hazard rate out of unemployment from the first day of unemployment. As a measure of the risk of participation we exploit that we actually estimate the individual's hazard rate into programme participation. We then use the estimated hazard rate into ALMPs as an explanatory variable in the hazard rate out of unemployment. If the coefficient on this hazard rate into programmes is positive, it implies that those faced with a higher risk of programme participation (without actually participating) leave unemployment faster than those with a lower risk of programme participation. We will interpret such an outcome as a threat effect of ALMPs on the exit rate out of unemployment.

The parameters of the model are estimated using an inflow sample of unemployed 
male workers collected from adminstrative records from the Danish National Labour Market Authority (NLMA). The data set is obtained directly from the NLMA and contains all spells of public income support experienced by residents in Denmark during 1998-2002. We analyse a sample consisting of $50 \%$ of the inflow into unemployment by workers eligible for unemployment insurance (UI) benefits. Our main finding is a considerable threat effect of ALMPs among unemployed men. Taking the threat effect into account, we then calculate the effects of active labour market policy regimes on unemployment duration and find that the Danish active labour market policy actually reduces average unemployment duration by approximately three weeks, mainly because of the threat effect.

The remainder of the paper is organised as follows: In the next section, we briefly review the available evidence on threat effects and programme effects. Section 3 briefly outlines the rules and regulations governing the Danish active labour market policy, while section 4 is devoted to a presentation of the data set. In section 5 , the econometric methodology is presented, and results are presented in Section 6. In section 7 we construct different measures of the effect of ALMPs, and section 8 contains a conclusion and a discussion of some policy considerations instigated by the results.

\section{A Brief Literature Review}

ALMPs have existed in both the U.S. and in Europe for several decades. Evaluations of their impacts have, however, been far more common in the U.S. than in Europe. Since the early sixties, ALMPs have been an integral part of U.S. labour market policy. Stanley et al. (1999) summarize the quantitative effects of several U.S. programmes. Although the effects are quite low, they do find that temporary employment subsidy programmes increase the probability of finding jobs in the subsidy period, but they also find that there are no long-term effects. Especially single mothers on social transfer schemes respond well to these programmes. In addition, they find that job search courses/counseling reduce individual unemployment duration. These results are roughly 
in agreement with those summarized by Heckman et al. (1999). Thus, ALMPs may improve the economic situation for those with a weak position in the labour market, but for other socio-economic groups the effects are smaller if at all positive. Moreover, different types of programmes have different impacts. Compared to the costs associated with AMLPs, the gains appear small. Consequently, the extent of ALMPs in the U.S. has been reduced in recent years (Kluwe \& Schmidt, 2002).

In Europe, there has been an increasing use of ALMPs in recent decades, but contrary to the U.S. - not the same willingness among policy makers to evaluate the impacts of these expensive programmes. Only during the past decade have researchers begun to evaluate the European programme experiences. Kluwe \& Schmidt (2002) summarize the European studies in the field since 1995. There are, naturally, large differences in the types of ALMPs and the extent to which they are used across Europe. The general conclusion is the same as for the U.S., though; the effects are modest.

In Denmark, the effectiveness of ALMPs has been investigated in a handful of studies, and the results are in line with the international experiences, see e.g. Bolvig et al. (2003), Rosholm \& Skipper (2003), and Munch \& Skipper (2003).

None of the studies mentioned above consider possible threat effects of ALMPs in their analyses. There are only a few studies which investigate this issue, and they indicate that the threat of (future participation in) ALMPs may actually affect the behaviour of unemployed in the labour market.

Black et al. (2003) discuss the effect of the Worker Profiling and Reemployment Service (WPRS) system. The programme applies 'profiling' to estimate the expected duration of unemployment, and subsequently offers job training and classroom training programmes to those workers with the highest probability of experiencing long-term unemployment. They find that WRPS reduces the average duration of unemployment by 2.2 weeks. Most of the effect, however, arises because many unemployed find jobs immediately after receiving written notification that they have been selected for participation in an ALMP, that is, before they actually participate. Black et al. (2003) conclude that the threat effect of the WPRS is the main gain of the system, and that 
the written notification motivates employable workers to find jobs faster than they otherwise would have.

There is a related literature on sanctioning unemployed who do not honour job search requirements. Lalive et al. (2002) show that there is an increase in the hazard rate of $28 \%$ at the time when an unemployed receives a written warning from the authorities that a sanction is pending due to suspicion of insufficient search activity. They also find indications that the sanctioning system affects the search intensity even before a warning is received.

These studies show that 'announced threats' affect the search behaviour of the unemployed. In Denmark, however, there is a threat of a somewhat different nature, in the sense that the universality of the active labour market policy regime implies that all unemployed who do not manage to find jobs must eventually participate in a programme (see the next section). This implies that there is a latent threat which could affect the search behaviour already from the first day in unemployment. Two studies (Ministry of Labour, 2000; Geerdsen, 2002) have attempted to document the presence of threat effects in the Danish context. They both find that the hazard rate out of unemployment increases the closer the individual comes to entering the 'intensified programme participation period' (in this period unemployed should should participate in programmes $75 \%$ of the time). By exploitation of changes in the laws governing entry into the period where programme participation is intensified, they show the presence of a threat effect. However, they only identify the change in the threat effect induced by a marginal change in legislation. In this paper we seek to estimate the entire threat effect from the first day of unemployment, using a different identification strategy.

\section{Danish Active Labour Market Policy}

In 1994, the law on active labour market policies introduced a system where active measures were used extensively to upgrade the skills of long-term unemployed to bring them back into employment. An unemployed can receive UI benefits for two periods. 
In the first period, which lasts for one year, the rate at which unemployed workers participate in programmes is quite low. After one year, however, the system requires that unemployed participate in a ALMP for at least $75 \%$ of the time. The second period lasts three years, after which a person who is still unemployed loses eligibility for UI benefits until an employment criterion is met. The employment criterion, which resets the clock that calculates the time until entering the second period, is that an individual has had at least 26 weeks of employment during the past 52 weeks. The UI-benefit payments are, however, constant in real terms throughout the four year period.

During the entire period of unemployment an unemployed worker can receive an 'offer' of programme participation from the local employment agency. This 'offer' has to be accepted, whether it is given in the first or in the second period - refusal cancels the right to receive UI benefits. ${ }^{2}$

The unemployed receives written information about the offer to participate in a specific programme shortly before the programme starts. Unfortunately, the time at which the letter of notification is sent is not available in the data set used in this study.

The decision to offer a specific programme to an unemployed is made by the employment agency. There are, however, meetings between the unemployed and the agency, were a plan to get the person back to work is produced. This plan could include participation in a given ALMP suggested by the unemployed person and agreed upon by the agency worker. There are also situations where the local labour market authorities (there are 15 of those in Denmark) decide to target programmes to specific groups of individuals. If a region experiences a drop in activity in an industry where a large part of the work force is occupied, they might want to train these individuals very early in their unemployment period to qualify them for work in other industries. The employment agencies are then obliged to follow the instructions given by the local labour market authorities. Information on these decisions are unfortunately not available. However,

\footnotetext{
${ }^{2}$ When a person has started in a programme, he has the option of complaining about the programme, and he may then be exempted from participation in that programme, if the cause for the complaint is found to be valid. However, this does not occur very often.
} 
it will become apparent in the analyses that some groups have higher probability of programme participation than others.

The ALMPs used in Denmark are categorized into four types by the NLMA:

- Private sector employment subsidies, where the (private sector) employer receives a subsidy corresponding to roughly $50 \%$ of the minimum wage and employs the individual on a time limited contract typically lasting 6-9 months.

- Public sector temporary jobs, typically lasting 6-12 months, in a public institution.

- Education/training, which consists of all types of classroom training from vocational training to computer courses, and in some cases also ordinary education. It typically lasts only a few months.

- Other programmes, which includes all programmes that cannot be classified as one of the three types above. Typically, these consist of job search assistance, programmes of compentence detection, building of self-esteem, etc. It is a very heterogeneous programme group.

\section{Data}

The data set used in this study is extracted from an event history data set developed by the Danish National Labour Market Authority. The event history is based on administrative registers, which record and govern the payments of public income transfers, as well as the register in which the employment agencies record unemployed's participation in ALMPs. This event history is used by the employment agencies for profiling, that is, to determine the risk that an individual becomes long-term unemployed, see Hammer et al. (2004). The event history is therefore considered to be very reliable.

The event history includes records of all time periods, measured on a weekly basis, in which a resident in Denmark has received a public income transfer. The data set used for this study covers the period January 1, 1998 - June 30, 2002. Because the data set 
is used for administrative purposes, it is frequently updated and therefore not merged with other registers containing information on such variables as education and work experience. However, certain information in the data set on UI fund membership may serve as a proxy for education, and it is possible to extract detailed past labour market histories, which may even be better than actual work experience for our purposes.

In this study, we are interested in the unemployment spells of workers who are eligible for UI benefits. An unemployment spell is defined as a period during which the person is either openly unemployed or participates in an ALMP. In order to be characterised as having found a job, an individual must have four consecutive weeks out of open unemployment during which he does not receive any other public income transfer either (nearly all non-working individuals in Denmark receive some type of income transfer). If the person has more than four weeks out of unemployment receiving other transfers, the unemployment spell will be characterised as right censored. Periods out of unemployment that are shorter than four weeks are treated as part of the unemployment spell. ${ }^{3}$

From this data set, we extract a sample of the inflow into unemployment for those eligible for - and receiving - UI benefits (those not eligible for UI benefits may instead receive social assistance). ${ }^{4}$ The sample consists of $50 \%$ of the entire inflow, selected at random. ${ }^{5}$

We further limit the sample to individuals aged between 25 and 59 years, both included. Those below 25 are excluded because for them an entirely different - and much stricter - set of rules apply (see Jensen et al., 2003). Those above 59 are excluded because special rules apply to them, too. In particular, the rules for participation in ALMPs are much laxer for this latter group.

\footnotetext{
${ }^{3}$ These periods typically consist of paternity leave (two weeks), holiday periods (typically up to three weeks), or short periods on sickness benefit payments.

${ }^{4}$ To be eligible for UI benefits, a worker must have been a member of a UI fund for at least one year and is employed for at least one year. The information available for UI recipients are of a much higher quality than for social assistance recipients. We therefore focus on UI recipients.

${ }^{5}$ We could not get access to a computer which was large enough to deal with the entire sample.
} 
In addition, all unemployment spells lasting less than four weeks are excluded from the sample in order to eliminate temporary layoff unemployment. Temporary layoffs are not directly identifiable with this data set, but we know from other studies that around $40 \%$ of all unemployment spells are temporary layoffs, and that more than $90 \%$ of these last four weeks or less, see e.g. Jensen and Westergaard-Nielsen (1990). Moreover, ALMPs are not that relevant to individuals who are only unemployed for a very short period.

Among the remaining observations we consider only those with no previous unemployment history in the sense that they have not recieved UI benefits during the past 52 weeks before the current unemployment spell, and therefore they all have a full year until they reach the period of intensified programme participation, see the description of the employment criterion in the last section. ${ }^{6}$ This restriction is imposed to avoid further complication of the empirical model. ${ }^{7}$ If an unemployed individual starts on his second programme during the same unemployment spell, the unemployment spell is treated as right censored at the time at which the second programme period starts. This is done in order to avoid having to model selection problems involved in sequences of programme participation. Each person can, of course, have several spells of unemployment in the sample period. A short description of the sample is given in Table 1.

\footnotetext{
${ }^{6}$ This sampling scheme implies that we remove the group of individuals who most often are hit by unemployment. It is plausible that this group is more 'immune' to the threat effect and that the estimated threat effect therefore will be upward biased.

${ }^{7}$ We would then have to model the remaining duration until programme participation conditional on the elapsed duration, and this is not straightforward in a bivariate setting with unobserved heterogeneity - the distribution of unobservables also depends on the elapsed duration.
} 


\begin{tabular}{lrr}
\hline \multicolumn{3}{c}{ Description of the sample } \\
\hline & Observations & $\%$ \\
Individuals & 55406 & \\
Unemployment spells & 93289 & \\
Unemployment spells with programme participation & 13260 & \\
Private sector employment subsidies & 756 & 5,70 \\
Public sector temporary jobs & 924 & 6,97 \\
Other programmes & 1423 & 10,73 \\
Education / training & 10157 & 76,60 \\
\hline
\end{tabular}

Table 1: Description of the sample

The final sample contains 55,406 individuals with a total of 93,289 unemployment spells that satisfy the selection criteria described above. In $14 \%$ of these unemployment spells the unemployed participates in some type of programme. $77 \%$ of thees programmes are in the category education/training, while only $6 \%$ are private sector employment subsidies. The share in public sector temporary jobs is $7 \%$, while the remaining $11 \%$ are in other programmes.

\subsection{Explanatory variables}

We use a number of explanatory variables in the analysis. These are: AGE30-39, AGE 40-49, AGE 50-59, with those aged 25-29 being the reference age category. Moreover, we have an indicator for whether the person lives alone; SINGLE. We have a set of indicators for UI fund membership: UI FUND CONSTRUCTION, UI FUND MANUFACTURING, UI FUND TECHNICIANS, UI FUND TRADE, UI FUND CLERICAL, UI FUND ACADEMICS, OTHER UI FUND, and UI FUND SELF-EMPLOYED. The reference category is membership of the UI FUND METAL. Some of these funds are industry based, while others are based on the educational achievements of the members. For example, UI FUND MANUFACTURING has mainly unskilled members who work in the manufacturing industry, UI FUND ACADEMICS is a collection of UI funds that insure academically educated workers, and the METAL UI fund mainly insures vocationally educated skilled workers in the metal industry. UI fund membership will 
therefore to some extent represent educational attainment, and also to some extent past industry. We have included two indicators for country of origin. IMMIGRANT FROM $D C$ refers to first and second generation immigrants from developed countries, while IMMIGRANT FROM LDC refers to first and second generation immigrants from less developed countries. ${ }^{8}$ The reference category is native Danes. Finally, we have access to a lot of information on past labour market history. First, we have the fraction of the time spent on public income transfers for each of the past five years. Moreover, we know how many spells receiving public income transfers the individual has experienced during the past five years. However, only the information from the two most recent years, TRANSFER DEGREE LAST YEAR, TRANSFER DEGREE TWO YEARS AGO, \# TRANSFER SPELLS LAST YEAR, and \# TRANSFER SPELLS LAST 2 $Y E A R S$ were significantly different from zero. Finally, we also had access to similar information of sickness periods, but all these variables turned out to be insignificant in the estimations and were therefore not used. Descriptive statistics for the variables can be found in Table A1 in the appendix. Although we do not have access to a 'kitchen sink' of variables, we do believe that we have access to a crucial set of variables when it comes to explaining participation in ALMPs and exits from unemployment.

\subsection{Transition rates into programmes and out of unemploy- ment}

The next section will reveal that a crucial assumption necessary for identification of the main parameters in our statistical model is that there is some random variation in the time until programme participation, since unemployed are not allowed to fully anticipate the moment of programme participation. To illustrate the variation in time until programme participation, we plot the Kaplan-Meier hazard rates for men from

\footnotetext{
${ }^{8}$ There were originally four indicators, separating also first from second generation immigrants in each category, but there were not many second generation immigrants from less developed countries, and for developed countries an F-test could not reject that the coefficients for first and second generation immigrants in all hazards were equal. Hence the two indicators were collapsed into one.
} 
unemployment into programmes in Figure 2. The Kaplan-Meier hazard rate in week $t$ depicts the fraction of workers still unemployed at the beginning of week $t$ who enter a programme during week $t$.

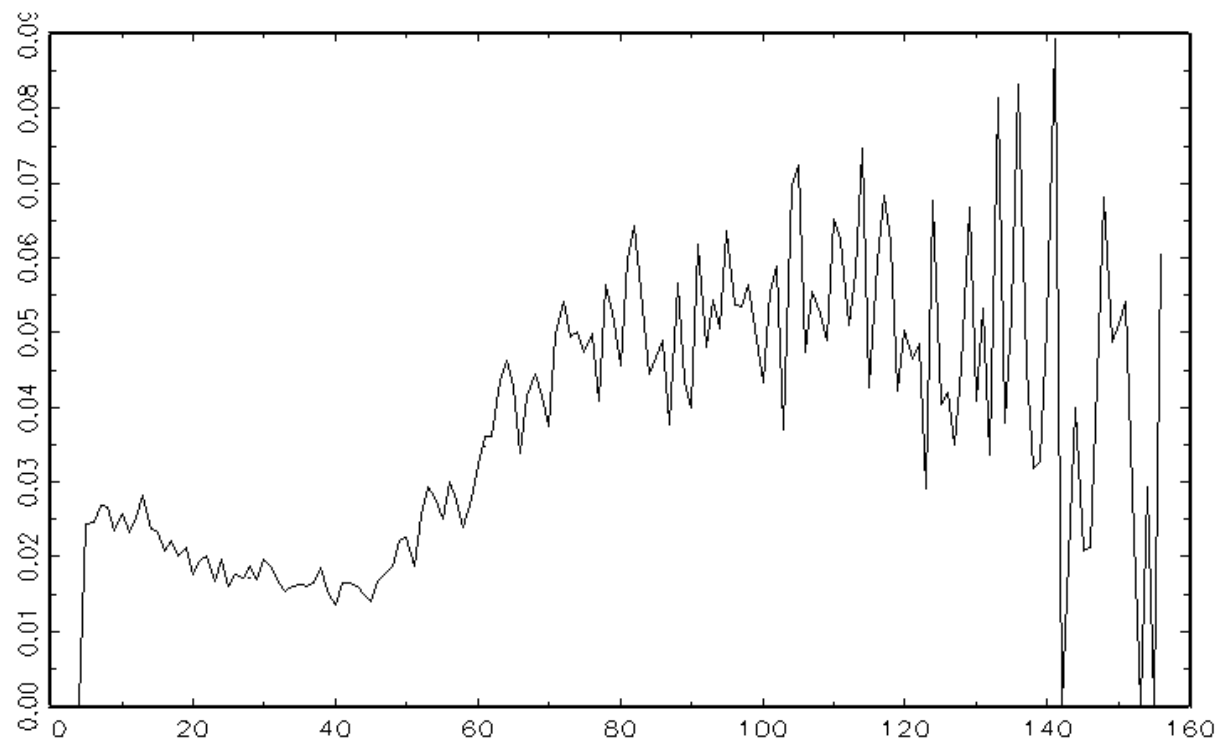

Figure 2. Kaplan-Meier hazard rate for the transition into AMLPs from open unemployment.

It is evident from the figure that some some unemployed workers participate in programmes very early in their unemployment spell (recall that all unemployed workers included in Figure 2 have an unemployment history of 0 weeks during the past 52 weeks before the current unemployment spell). After one year of open unemployment (unemployment without programme participation), the hazard rate into programmes increases and stays high throughout the remainder of the unemployment spell. There is consequently a lot of variation in the time until programme participation. Note that quite a few unemployed workers do not enter a programme until they have spent significantly more than a year in open unemployment. This is quite surprising, given the rules described in the previous section. A major reason for this postponement of 
programme participation is capacity constraints at the employment agencies; the rules concerning the intensity of programme participation meant that the case workers had difficulties keeping up.

Figure 3 shows the Kaplan-Meier hazard rates into each of the four programme types. Note that the hazard rates have been smoothed using a three week centered moving average in order to present a clearer picture. It is evident from the figure that education/training is the most frequently used programme type. The figure also reveals that as unemployment duration increases, and especially after one year of unemployment, the relative importance of other programmes and public sector temporary jobs increases. One reason for the latter phenomenon is that the municipal authorities traditionally have had a status as employer of last resort, that is, if all else fails, an unemployed person will be assigned to a temporary job in the public sector (i.e. in the municipality). It would seem that 'other programmes' to some extent fulfill the same role. Private sector employment subsidies and education/training also have increasing hazard rates after one year of open unemployment, but the relative increase is much more modest - transition rates into education/training and private sector employment subsidies double, while transition rates into other programmes and public sector temporary jobs both increase by a factor 5-6. Still, by far the most important programme type at any unemployment duration is education/training. 


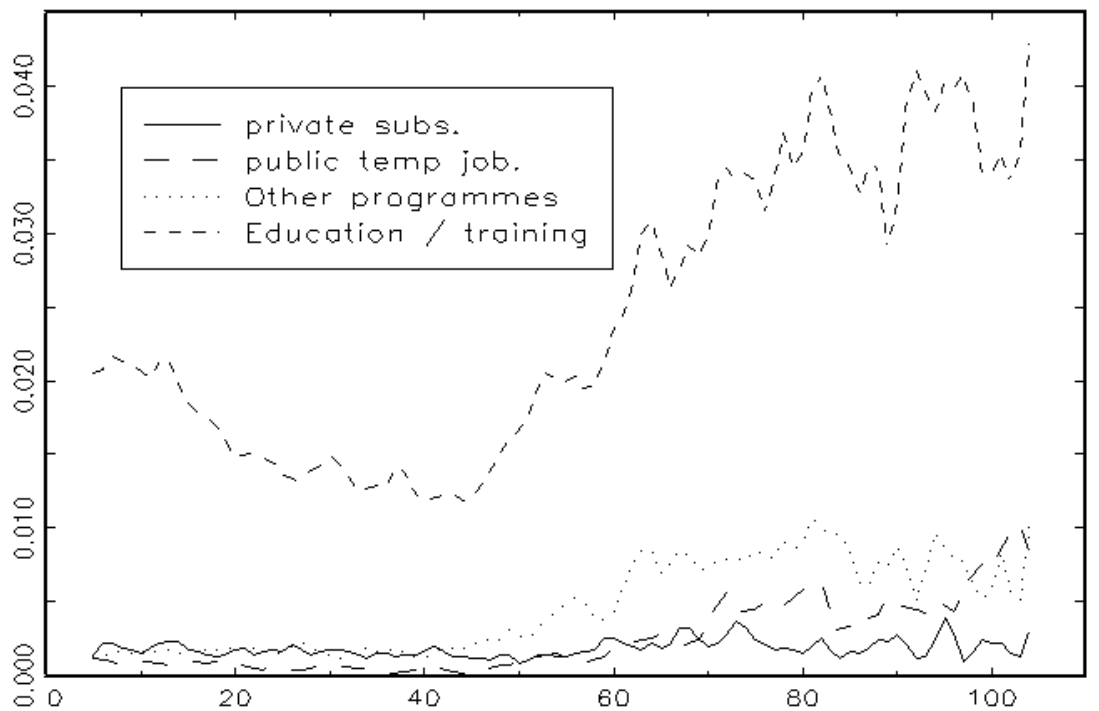

Figure 3. Kaplan-Meier transition rates into four different AMLPs from open unemployment.

In Figure 4 we plot the Kaplan-Meier hazard rates for the transition out of unemployment. We plot the hazard rate separately for unemployed workers who have participated in an ALMP and those who have not to illustrate a point: Since participation in a programme is compulsory after some time in unemployment, one might fear that it would be difficult to find a comparison group of non-participants at longer unemployment durations. However, Figure 4 reveals that there is a group of unemployed workers who do not participate in programmes, even among those with long unemployment durations. These are probably not a randomly selected group of long-term unemployed. The group of non-participants consists both of resourceful unemployed workers who are able to find jobs before participation becomes compulsory and of unemployed with fewer resources who, despite long unemployment spells, have not participated in programmes. One should therefore not interpret the difference in the raw hazard rates. The empirical model specified in the next section is designed to handle non-random programme participation. 
In the curve for non-participants we see an interesting jump in the hazard rate around one year of unemployment. This jump could be indicative of the presence of a threat effect, since one year of unemployment is the time at which the transition rate into programmes increases due to the rules governing programme participation.

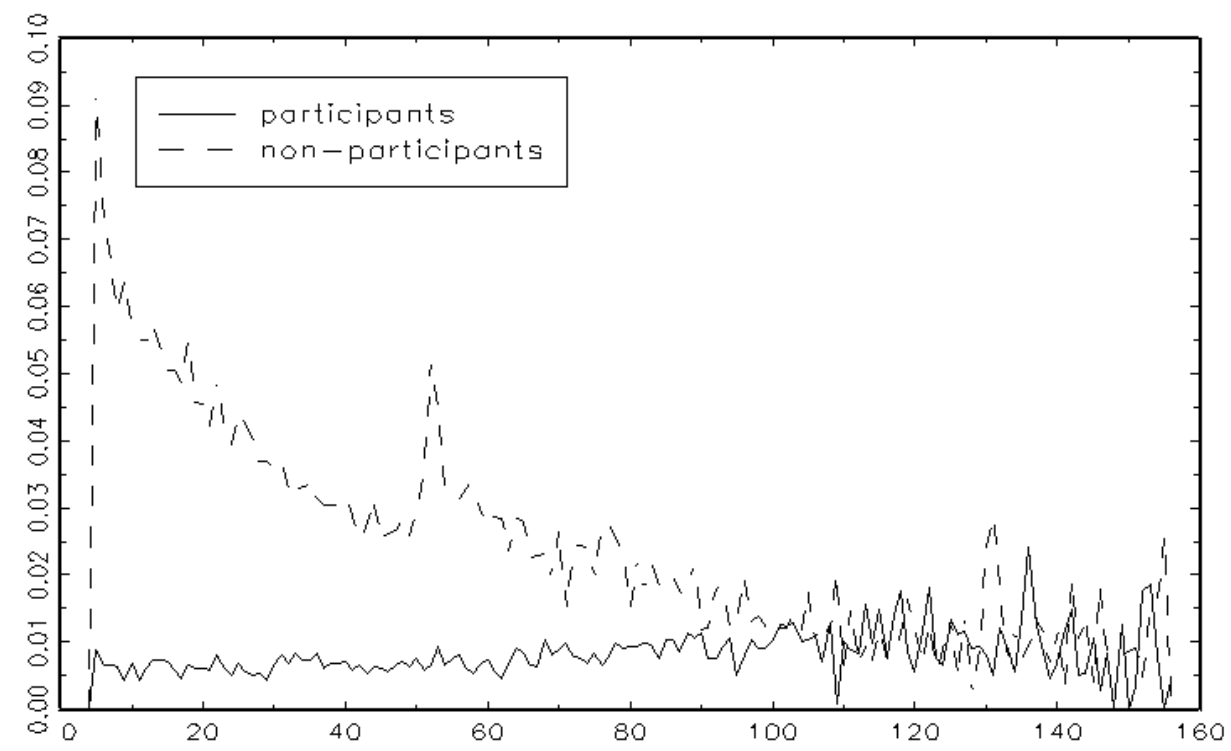

Figure 4. Kaplan-Meier hazard rates for the transition out of unemployment.

\section{$5 \quad$ Econometric model}

The econometric model is based on a combination of two existing models; the timing-ofevents model for identifying treatment effects in a duration model framework, developed by Abbring \& van den Berg (2003), and a dependent hazard rates model, developed by Lillard (1993) and further analyzed and used by Rosholm \& Svarer (2001).

The timing-of-events model simultaneously models the transition rate out of, say, unemployment, and the transition rate into ALMPs. The model is intended to correct for non-random selection into programmes, with respect to observed as well as unob- 
served variables. Abbring \& van den Berg (2003) show that with an assumption of 1) mixed proportional hazards and 2) a non-defective distribution of time until participation in ALMPs given observed explanatory variables, the parameters of interest - say, the effect of participation in ALMPs - are identified non-parametrically. The implication is that there is no need for an exclusion restriction, that is, a variable which appears in the selection equation, but which does not affect the outcome variable, in this case the hazard rate out of unemployment. The intuition is that random variation in the timing of the event of participation in ALMPs separates the treatment effect from the distribution of unobserved heterogeneity, which is assumed to be time-invariant.

The dependent hazard rates model estimates two hazard rates, but allows one of them to depend explicitly on the other. In this case the hazard rate from unemployment into a new job may depend on the hazard rate into participation in an ALMP.

When we combine the two approaches, it is possible to estimate both the threat effect of ALMPs as well as the locking-in and post-programme effects, while taking into account the endogeneity of participation in ALMPs. The idea is that anticipation of participation in ALMP may affect the hazard rate out of unemployment from the first day of unemployment. As a measure of the risk of participation we exploit that we actually estimate the individual's hazard rate into programme participation. We then use the estimated hazard rate into ALMPs as an explanatory variable in the hazard rate out of unemployment. If the coefficient on this hazard rate into programmes is positive, it implies that those faced with a higher risk of programme participation (without actually participating) leave unemployment faster than those with a lower risk of programme participation. We will interpret such an outcome as a threat effect of ALMPs on the exit rate out of unemployment.

Let $T_{u}$ be a random variable which denotes the duration of an unemployment spell, and let $T_{p}$ be another random variable which denotes the time from entry into unemployment until participation in the first ALMP. The implication is that if $T_{p}<T_{u}$ we observe the individual participating in an ALMP during the unemployment spell. If $T_{p}=T_{u}$, then it is implied that $T_{p}$ is censored, and the individual did not participate 
in an ALMP before $T_{u}$.

Let $\mathbf{X}(t)$ be a vector of observed exogenous explanatory variables, and let and $V_{u}$, and $V_{p}=\left(V_{p 1}, V_{p 2}, V_{p 3}, V_{p 4}\right)$, denote unobserved variables possibly affecting the exit rate out of unemployment and the entry rates into ALMPs, of which there are four different types.

The hazard into ALMPs is the sum of four cause-specific hazard rates, one for each type of ALMP

$$
\theta_{p}\left(t_{p} \mid \mathbf{x}\left(t_{p}\right), v_{p}\right)=\sum_{i=1}^{4} \theta_{p i}\left(t_{p} \mid \mathbf{x}\left(t_{p}\right), v_{p i}\right) .
$$

Each of these cause-specific hazards is assumed to be of the mixed proportional hazard type,

$$
\theta_{p i}\left(t_{p} \mid \mathbf{x}\left(t_{p}\right), v_{p i}\right)=\lambda_{p i}\left(t_{p}\right) \exp \left(\mathbf{x}\left(t_{p}\right) \boldsymbol{\beta}_{p i}+v_{p i}\right) \text {. }
$$

Next, we define two time varying vectors of indicator variables, $\mathbf{d}_{1}(t)$ and $\mathbf{d}_{2}(t)$ : $\mathbf{d}_{1}(t)$ is a $4 \mathrm{x} 1$ vector, and the $i$ 'th element takes the value 1 if the individual participates in an ALMP of type $i$ at time $t$ and takes the value 0 otherwise. Note that at most one element of $\mathbf{d}_{1}(t)$ can take the value 1 at time $t$. Similarly, the $i$ th element of $\mathbf{d}_{2}(t)$ (which is also $4 \times 1$ ) takes the value 1 if the individual has completed an ALMP of type $i$ within the last 26 weeks. Note that the implication is that we only allow ALMPs to affect the hazard rate out of unemployment up to 26 weeks after completion.

Assuming once again a mixed proportional hazard rate, the hazard rate out of unemployment can be written as

$$
\theta_{u}\left(t_{u} \mid \mathbf{x}\left(t_{u}\right), \mathbf{d}_{1}\left(t_{u}\right), \mathbf{d}_{2}\left(t_{u}\right), v_{u}\right)=\lambda_{u}\left(t_{u}\right) \exp \left(\mathbf{x}\left(t_{u}\right) \boldsymbol{\beta}_{u}+\mathbf{d}_{1}\left(t_{u}\right) \delta_{1}+\mathbf{d}_{2}\left(t_{u}\right) \delta_{2}+v_{u}\right)
$$

The parameter $\delta_{1}$ measures the effect of being in a programme, which we refer to as the locking-in effect, while $\delta_{2}$ measures the effect of having completed a programme, that is, the post-programme effect. The timing-of-events model takes into account potential endogeneity of $\mathbf{d}_{1}(t)$ and $\mathbf{d}_{2}(t)$ by allowing for correlation between the two unobserved 
components $V_{u}$ and $V_{p}$. That is, this methods allows for selection on unobservables as well as observed explanatory variables.

Our primary interest here, however, is the estimation of the threat effect, and for that, the model specified above has to be modified slightly. The threat effect arises if the individual reacts to a perceived risk of participation in programmes in the future. A direct measure of the instantaneous risk of programme participation is the hazard rate into ALMPs, $\theta_{p}\left(t_{p} \mid \mathbf{x}_{t_{p}}, v_{p}\right)$, which measures the the risk of programme participation in week $t_{p}$, given that the individual has not participated in a programme previously in the current unemployment spell. ${ }^{9}$ We make the assumption that the threat effect depends on the sum of the four cause-specific hazard rates into different programme types, that is, we assume that an individual does not know in advance the programme into which he will be assigned. Hence, we do not estimate a separate coefficient for each programme type. The hazard rate out of unemployment is specificed as

$$
\begin{gathered}
\theta_{u}\left(t_{u} \mid \mathbf{x}\left(t_{u}\right), \mathbf{d}_{1}\left(t_{u}\right), \mathbf{d}_{2}\left(t_{u}\right), v_{u}, v_{p}\right)= \\
\lambda_{u}\left(t_{u}\right) \exp \left[\begin{array}{c}
\mathbf{x}\left(t_{u}\right) \boldsymbol{\beta}_{u}+\mathbf{d}_{1}\left(t_{u}\right) \delta_{1}+\mathbf{d}_{2}\left(t_{u}\right) \delta_{2}+v_{u} \\
+\mathbf{1}\left\{\mathbf{d}_{1}\left(t_{u}\right)+\mathbf{d}_{2}\left(t_{u}\right)=0\right\} \cdot \theta_{p}\left(t_{u} \mid \mathbf{x}\left(t_{u}\right), v_{p}\right) \cdot \delta_{0}
\end{array}\right] .
\end{gathered}
$$

The first line in the exponential function corresponds to the specification in equation 3 , while the second line introduces the threat effect. The threat effect only exists until the person starts participating in a programme, that is, as long as both $\mathbf{d}_{1}\left(t_{u}\right)=0$ and $\mathbf{d}_{2}\left(t_{u}\right)=0 .{ }^{10}$ We hereby ignore threat effects that arise after completed programmes.

\footnotetext{
${ }^{9}$ Although not explicitly stated we assume that the individuals behave according to a nonstationary search model. The nonstationarity arises from the change in participation risk. We, however, follow van den Berg (1990) and Narendranathan (1993) and assume that the individuals only use the current values of the parameters of the search model when they make desicions. That is, they are assumed to be naive searchers in the sense that they react to the current level of participation risk - not expectations about future levels of participation risks. This assumption simplifies the calculations tremendously and still provides an intuitive illustration of the potential threat effect.

${ }^{10}$ Actually, the requirement is stricter, given our assumption that the post-programme effect only
} 
Such effects will be included in $\delta_{2}$. In specification 4 we impose a time-invariant threat effect parameter. In the empirical analysis we also allow for time-varying threat effect parameters. $^{11}$

If we define $C_{u}$ as an indicator variable that takes the value 1 for completed unemployment spells and 0 for right censored unemployment spells, the contribution to the likelihood function of one individual with $J$ unemployment spells, given observed and unobserved characteristics, is

$$
\begin{aligned}
\mathcal{L}\left(v_{u}, v_{p}\right)= & \prod_{j=1}^{J} \theta_{p}\left(t_{p j} \mid \mathbf{x}\left(t_{p j}\right), v_{p}\right)^{1\left\{t_{p}<t_{u}\right\}} \cdot \theta_{u}\left(t_{u j} \mid \mathbf{x}\left(t_{u j}\right), \mathbf{d}_{1}\left(t_{u j}\right), \mathbf{d}_{2}\left(t_{u j}\right), v_{u}, v_{p}\right)^{c_{u}} \\
& \times \exp \left[-\int_{0}^{t_{p j}} \theta_{p}\left(s \mid \mathbf{x}(s), v_{p}\right) d s-\int_{0}^{t_{u j}} \theta_{u}\left(t \mid \mathbf{x}(t), \mathbf{d}_{1}(t), \mathbf{d}_{2}(t), v_{u}, v_{p}\right) d t\right]
\end{aligned}
$$

and the likelihood function is then

$$
\mathcal{L}=\iint \mathcal{L}\left(v_{u}, v_{p}\right) d G\left(v_{u}, v_{p}\right)
$$

where $G(\cdot, \cdot)$ is a bivariate distribution function for $\left(v_{u}, v_{p}\right)$.

\subsection{Identification}

Identification in the timing-of-events model is based on two assumptions; a distributional assumption that requires that the hazard rates are specified as mixed proportional hazards, and a 'no anticipation' assumption. The latter assumption implies that the individual is allowed to know the distribution of time until programme participation, but not the exact moment at which he will participate. The inclusion of the threat effect does not jeopardize these assumptions per se. However, we introduce a parameter that affects the hazard rate out of unemployment in exactly the time interval which is exists for 26 weeks after the end of the programme, but we will use the condition stated here for ease of exposition.

${ }^{11}$ Note, however, that the threat effect is time-varying even if the parameter $\delta_{0}$ is time-invariant, because the hazard rate $\theta_{p}\left(t_{p} \mid x_{t_{p}}, v_{p}\right)$ is time-varying. 
used for identification in the timing-of-events model, namely the time until programme participation, so it is necessary to discuss the conditions for identification.

In fact, the model is identified given the assumptions stated above, and the argument is the following: The parameters in the hazard rate for time until programme participation are identified from information on times of programme participation. The problem is that the same explanatory variables enter both hazard rates. However, the explanatory variables in the participation hazard enters in four different ways (in the four different cause-specific hazard rates), each of which are multiplied onto a baseline hazard which is time-varying. The implication is that the participation hazard will be time-varying, and the impact of the explanatory variables in this hazard rate will be shifted by shifts in each of these four baseline hazards. This essentially implies that the multicolinearity problem in the hazard rate out of unemployment disappears. The time variation in the four baseline hazards implies that the explanatory variables embedded in the participation hazard will show independent time variation from the same explanatory variables in the hazard rate out of unemployment.

Of course, one could also impose an exclusion restriction to obtain identification, but valid variables to use are often hard to find. As noted by Abbring and van den Berg (2003), "a variable that is observed by the analyst is often also observable to the individuals under consideration. If such a variable affects the treatment process then a rational individual will take this variable into account in determining his optimal strategy. This behaviour affects the rate at which the individual leaves the state of interest. As a result, exclusion restrictions are difficult to justify".

\subsection{Parametrization}

We assume that all baseline hazard rates are piecewise constant, that is $\lambda_{j}(t)=$ $\exp \left(\alpha_{j m}\right), m=1, \ldots, M_{j}$, where $M_{j}$ is the number of intervals for baseline hazard $j$. For all hazard rates, we use the following cut-off points for the intervals (recall that unemployment duration and time until programme participation are both measured in 
weeks): 14, 24, 40, 44, 48, 52, 56, 60, 96, 112, 156. We use a finer grid around one year duration, because this is the time at which programme participation rates are intensified dramatically. We use the same duration intervals for all hazard rates to ensure that any estimated threat effects do not capture duration dependence present in one hazard but unaccounted for in the other.

For the mixture distribution, we apply a discrete distribution with two points of support for each of the marginal distributions of the unobserved variables. Let $\left(v_{u}^{1}, v_{u}^{2}\right)$ and $\left(v_{p i}^{1}, v_{p i}^{2}\right), i=1,2,3,4$, be the mass-points of $V_{u}$ and $V_{p i}$, respectively. The associated probabilities are then as follows:

$$
\begin{aligned}
& P_{1}=\operatorname{Pr}\left(V_{u}=v_{u}^{1}, V_{p 1}=v_{p 1}^{1}, V_{p 2}=v_{p 2}^{1}, V_{p 3}=v_{p 3}^{1}, V_{p 4}=v_{p 4}^{1}\right) \\
& P_{2}=\operatorname{Pr}\left(V_{u}=v_{u}^{2}, V_{p 1}=v_{p 1}^{1}, V_{p 2}=v_{p 2}^{1}, V_{p 3}=v_{p 3}^{1}, V_{p 4}=v_{p 4}^{1}\right) \\
& P_{3}=\operatorname{Pr}\left(V_{u}=v_{u}^{1}, V_{p 1}=v_{p 1}^{2}, V_{p 2}=v_{p 2}^{2}, V_{p 3}=v_{p 3}^{2}, V_{p 4}=v_{p 4}^{2}\right) \\
& P_{4}=\operatorname{Pr}\left(V_{u}=v_{u}^{2}, V_{p 1}=v_{p 1}^{2}, V_{p 2}=v_{p 2}^{2}, V_{p 3}=v_{p 3}^{2}, V_{p 4}=v_{p 4}^{2}\right)
\end{aligned}
$$

with $0 \leq P_{i} \leq 1$ for $i=1, \ldots, 4$, and $\sum_{i=1}^{4} P_{i}=1$. Note that the unobserved heteregeneity terms are restricted to be perfectly correlated in the four cause-specific hazard rates into programmes. This is also called a factor-loading specification. It restricts the correlation between $V_{p i}$ and $V_{p j}$ to be either 1 or -1 if $i \neq j$. The correlation between $V_{u}$ and $V_{p}$ is unrestricted, which is important, since this is the correlation which is intended to correct for selection on unobservables. We normalize the distribution of the unobservables by setting $v_{j}^{1}=0$ for all hazard rates. This is done instead of normalising e.g. the mean of the mixture distribution to one.

\section{Results}

In this section we present the main results. We will focus exclusively on the three types of effects discussed above and leave the effects of other explanatory variables out. The full estimation results for the most general model with time-varying threat effects are 
available in Tables A2 and A3 in the Appendix. ${ }^{12}$ The model without threat effects is estimated along the lines of the standard timing-of-events model, that is, it is based on model 3 above, while the model with threat effects is based on model 4 .

Table 2 shows the estimated average locking-in and post-programme effects of participation in ALMPs for those who participate, as well as the estimated threat effects. Notice that the threat effect parameter is allowed to be time-varying in this specification. Specifically, we allow the threat effect parameter to change at 20, 40, and 52 weeks of unemployment duration, since we would expect the threat effect to become more important as the individual approaches the one year period. Columns 2 and 3 show the parameter estimates and associated standard errors of the model where the threat effect is included and estimated in the model, while columns 4 and 5 show the parameter estimates and standard errors of the parameters in the timing-of-events model where we leave out the threat effect.

\footnotetext{
${ }^{12}$ Other results are available upon request.
} 
Table 2. Threat Effects, Locking-in Effects, and Post-Programme EFFECTS OF ALMPS

\begin{tabular}{l|rrrr}
\hline \hline & \multicolumn{2}{c}{$\begin{array}{c}\text { Model with } \\
\text { threat effect }\end{array}$} & \multicolumn{2}{c}{$\begin{array}{c}\text { Model without } \\
\text { threat effect }\end{array}$} \\
& Coeff. & Std.err. & Coeff. & Std.err \\
\hline Threat effect & & & & \\
0-20 weeks of unemployment & $\mathbf{1 4 . 1 6}$ & $\mathbf{2 . 2 5}$ & & \\
20-40 weeks of unemployment & $\mathbf{2 1 . 9 7}$ & $\mathbf{3 . 4 3}$ & & \\
40-52 weeks of unemployment & $\mathbf{2 8 . 7 9}$ & $\mathbf{4 . 3 9}$ & & \\
52- weeks of unemployment & 0.90 & 1.85 & & \\
Private sector empl. subsidiy & & & & \\
Locking-in effect & $\mathbf{- 0 . 2 0 3 5}$ & $\mathbf{0 . 0 7 6 9}$ & $\mathbf{- 0 . 2 8 0 7}$ & $\mathbf{0 . 0 7 9 8}$ \\
Post-programme effect & $\mathbf{0 . 5 2 8 8}$ & $\mathbf{0 . 0 8 8 3}$ & $\mathbf{0 . 4 7 9 6}$ & $\mathbf{0 . 0 8 8 8}$ \\
Public sector temporary jobs & & & & \\
Locking-in effect & $\mathbf{- 0 . 5 7 3 3}$ & $\mathbf{0 . 1 0 4 8}$ & $\mathbf{- 0 . 6 4 3 8}$ & $\mathbf{0 . 1 0 2 9}$ \\
Post-programme effect & 0.1309 & 0.1138 & 0.1060 & 0.1136 \\
Other programmes & & & & \\
Locking-in effect & 0.0282 & 0.0873 & -0.0372 & 0.0863 \\
Post-programme effect & -0.0203 & 0.0889 & -0.0769 & 0.0878 \\
Education / training & & & & \\
Locking-in effect & $\mathbf{- 0 . 6 8 4 5}$ & $\mathbf{0 . 0 3 2 3}$ & $\mathbf{- 0 . 8 2 8 2}$ & $\mathbf{0 . 0 2 9 2}$ \\
Post-programme effect & $\mathbf{0 . 2 7 0 8}$ & $\mathbf{0 . 0 3 0 1}$ & $\mathbf{0 . 1 3 3 3}$ & $\mathbf{0 . 0 2 7 8}$ \\
\hline \hline
\end{tabular}

Looking at columns 2 and 3, we find large and significant threat effects. Moreover, the threat effect parameter increases up to one year of unemployment. After one year of unemployment the threat effect disappears entirely. This suggests that the threat effect has an impact on some individuals, and causes them to find jobs before they enter the period where programme participation is intensified. Those who remain unemployed more than 52 weeks, on the other hand, may not perceive programme participation as 
a threat. On the contrary, they may even expect to gain from participation in some of these programmes. The results for some programme types seem to suggest that this is the case. The empirical importance of the threat effect does, however, also depend on the size of the hazard rate into programme participation, which is multiplied onto the threat effect parameter. This hazard rate is quite low during the first 20 weeks of open unemployment, see the parameter estimates in Table A2 in the Appendix (and the Kaplan-Meier plot in Figure 3). This issue is analysed further in the next section.

For private sector employment subsidies, we find moderately small locking-in effects and fairly large post-programme effects, suggesting that private sector employment subsidies are quite good for bringing unemployed workers out of unemployment. For temporary jobs in the public sector, however, there is a larger locking-in effect and an insignificant, albeit positive, post-programme effect. For other programmes, which is also a quite heterogeneous programme category, neither locking-in nor post-programme effects are significant. For educational and training programmes there are large lockingin effects, which is partially a good thing as it implies that participants are likely to complete their training. Moreover, there are fairly large and significantly positive postprogramme effects.

Comparing columns 2 and 4, note also how the inclusion of the threat effect has exactly the hypothesized effect illustrated in Figure 1, namely that it reduces the locking-in effect and increases the post-programme effect. This is because by taking the threat effect into account, the counterfactual situation is changed to one with no active labour market policies at all.

The results regarding locking-in and post-programme effects are largely in line with results from other studies, both in Denmark and internationally. Our finding of a threat effect is consistent with the results of Mininistry of Labour (2000) and Geerdsen (2002), who both find evidence that indicates the presence of a threat effect. Moreover, Black et al. (2003) find similar evidence for the U.S., while Lalive et al. (2002) find compelling evidence of a threat effect of search requirements and sanctions.

It is hard to derive the net effect of an active labour market policy regime as com- 
pared to a passive one, and in any event, different counterfactual situations might be of interest, so in the next section we turn to the issue of measuring the net effect of an active labour market policy regime and investigate the net effects of participation for individual participants. ${ }^{13}$

\section{Analysis}

In the following section, we calculate the expected duration of unemployment for an average person in different counterfactual situations in order to give a quantitative measure of the net effects of ALMPs. The average person has the characteristics of an average individual in the sample, see Table A1 the Appendix.

The person can participate in one of the four programmes. If he participates, he participates after 52 weeks' unemployment, and the duration of the participation period is 26 weeks for private sector employment subsidies and for temporary jobs in the public sector, it is 16 weeks for education/training, and 8 weeks for other programmes. These durations correspond to average observed durations of programmes. In the calculations below, the programme duration is denoted $\tau_{p}$.

The expected duration of an unemployment spell can be estimated based on the

\footnotetext{
${ }^{13}$ We have also estimated these models for women. Our findings, which are available upon request, show that for women, the threat effect is present, but much smaller. Moreover, the effects of programmes are less favourable than they are for men, so overall, ALMPs have a much smaller impact on women than on men.
} 
estimated parameter values from the duration model as

$$
\begin{aligned}
& E\left[T_{u} \mid\left\{\mathbf{x}(t), \mathbf{d}_{1}(t), \mathbf{d}_{2}(t)\right\}_{0}^{\infty} ; \delta_{0}\right] \\
= & \iint E\left[T_{u} \mid\left\{\mathbf{x}(t), \mathbf{d}_{1}(t), \mathbf{d}_{2}(t)\right\}_{0}^{\infty}, v_{u}, v_{p} ; \delta_{0}\right] d G v_{u}, v_{p} \\
= & \sum_{i=1}^{2} \sum_{j=1}^{2} \operatorname{Pr}\left(v_{u i}, v_{p j}\right) \int_{0}^{\infty} S\left(t \mid\left\{\mathbf{x}(t), \mathbf{d}_{1}(t), \mathbf{d}_{2}(t)\right\}_{0}^{\infty}, v_{u i}, v_{p j} ; \delta_{0}\right) d t \\
= & \sum_{i=1}^{2} \sum_{j=1}^{2} \operatorname{Pr}\left(v_{u i}, v_{p j}\right) \sum_{k=1}^{\infty} \exp \left[-\sum_{s=1}^{k} h_{u}\left(s \mid \mathbf{x}(s), \mathbf{d}_{1}(s), \mathbf{d}_{2}(s), v_{u}, v_{p} ; \delta_{0}\right)\right]
\end{aligned}
$$

where the $\delta_{0}$ indicates the presence of the threat effect. In practice, we replace $\infty$ in the sums with a large number (520 weeks). In the calculations below, we either set $\delta_{0}=\widehat{\delta}_{0}$ or $\delta_{0}=0$. The first situation corresponds to including the threat effect in the calculated outcome, that is, it corresponds to a world with ALMPs. The second situation corresponds to a situation where there is no threat effect, that is, a situation where there are no ALMPs. We calculate the following effects below:

$\Delta_{1}$ : The effect of programme participation in a system with ALMPs compared to no programme participation in a system with no ALMPs (i.e. no threat effect). This effect therefore measures the total effect of ALMPs on expected unemployment duration:

$$
\begin{aligned}
\Delta_{1} & = \\
E\left[T_{u} \mid\left\{\mathbf{x}(t), \mathbf{d}_{1}(t)\right.\right. & \left.\left.=\mathbf{1}\left[52<t \leq 52+\tau_{p}\right], \mathbf{d}_{2}(t)=\mathbf{1}\left[52+\tau_{p}<t \leq 78+\tau_{p}\right]\right\}_{0}^{\infty} ; \delta_{0}=\widehat{\delta}_{0}\right] \\
-E\left[T_{u} \mid\left\{\mathbf{x}(t), \mathbf{d}_{1}(t)\right.\right. & \left.\left.=0, \mathbf{d}_{2}(t)=0\right\}_{0}^{\infty} ; \delta_{0}=0\right] .
\end{aligned}
$$

$\Delta_{2}$ : The effect of programme participation and threat effect compared to no programme participation, but exposure to a threat effect (that is, a system of ALMPs). This effect therefore measures the pure net effect of programme participation:

$$
\begin{aligned}
\Delta_{2} & = \\
E\left[T_{u} \mid\left\{\mathbf{x}(t), \mathbf{d}_{1}(t)\right.\right. & \left.\left.=\mathbf{1}\left[52<t \leq 52+\tau_{p}\right], \mathbf{d}_{2}(t)=\mathbf{1}\left[52+\tau_{p}<t \leq 78+\tau_{p}\right]\right\}_{0}^{\infty} ; \delta_{0}=\widehat{\delta}_{0}\right] \\
-E\left[T_{u} \mid\left\{\mathbf{x}(t), \mathbf{d}_{1}(t)\right.\right. & \left.\left.=0, \mathbf{d}_{2}(t)=0\right\}_{0}^{\infty} ; \delta_{0}=\widehat{\delta}_{0}\right] .
\end{aligned}
$$


$\Delta_{3}:$ The threat effect:

$$
\begin{aligned}
\Delta_{3} & = \\
E\left[T_{u} \mid\left\{\mathbf{x}(t), \mathbf{d}_{1}(t)\right.\right. & \left.\left.=0, \mathbf{d}_{2}(t)=0\right\}_{0}^{\infty} ; \delta_{0}=\widehat{\delta}_{0}\right] \\
-E\left[T_{u} \mid\left\{\mathbf{x}(t), \mathbf{d}_{1}(t)\right.\right. & \left.\left.=0, \mathbf{d}_{2}(t)=0\right\}_{0}^{\infty} ; \delta_{0}=0\right] .
\end{aligned}
$$

To sum up, $\Delta_{1}(\cdot)$ denotes the total effect of programme participation and the threat implied by the active labour market policy regime, whereas $\Delta_{2}(\cdot)$ denotes the effect of programme participation alone. Note that the latter does not correspond exactly to the effect that would arise if the threat effect were ignored in the estimation process, since that would change the estimated coefficients. This implies that the estimated effects in this case would be below $\Delta_{2}$. Note also that the identity $\Delta_{1} \equiv \Delta_{2}+\Delta_{3}$ is implied by these equations. Table 3 reports the expected durations and the estimated effects. 
Table 3. Effects of ALMPs and Threats on the Duration of UNEMPLOYMENT.

\begin{tabular}{l|ccccccc}
\hline \hline & \multicolumn{4}{|c}{ Expected duration } & \multicolumn{3}{c}{ Effect } \\
\hline & Participation & No participation & \multicolumn{1}{c}{} \\
\hline$\Delta_{1}$ (Private sector empl. subsidy) & $\mathbf{3 2 . 5 0}$ & 0.67 & $\mathbf{3 6 . 2 4}$ & 0.58 & $\mathbf{- 3 . 7 3}$ & 0.62 \\
$\Delta_{2}$ (Private sector empl. subsidy) & $\mathbf{3 2 . 5 0}$ & 0.67 & $\mathbf{3 3 . 3 8}$ & 0.76 & -0.87 & 0.47 \\
& & & & & & \\
$\Delta_{1}$ (Public sector temporary jobs) & $\mathbf{3 5 . 0 4}$ & 0.76 & $\mathbf{3 6 . 2 4}$ & 0.58 & $\mathbf{- 1 . 2 0}$ & 0.66 \\
$\Delta_{2}$ (Public sector temporary jobs) & $\mathbf{3 5 . 0 4}$ & 0.76 & $\mathbf{3 3 . 3 8}$ & 0.76 & $\mathbf{1 . 6 5}$ & 0.52 \\
& & & & & & \\
$\Delta_{1}$ (Other programmes) & $\mathbf{3 3 . 4 0}$ & 0.64 & $\mathbf{3 6 . 2 4}$ & 0.58 & $\mathbf{- 2 . 8 3}$ & 0.52 \\
$\Delta_{2}$ (Other programmes) & $\mathbf{3 3 . 4 0}$ & 0.64 & $\mathbf{3 3 . 3 8}$ & 0.76 & 0.01 & 0.34 \\
& & & & & & \\
$\Delta_{1}$ (Education / training) & $\mathbf{3 3 . 9 5}$ & 0.58 & $\mathbf{3 6 . 2 4}$ & 0.58 & $\mathbf{- 2 . 2 9}$ & 0.42 \\
$\Delta_{2}$ (Education / training) & $\mathbf{3 3 . 9 5}$ & 0.58 & $\mathbf{3 3 . 3 8}$ & 0.76 & $\mathbf{0 . 5 6}$ & 0.14 \\
$\Delta_{3}$ & & & & & & \\
\hline \hline
\end{tabular}

Note: Standard errors are calculated by drawing 500 parameter vectors from a multivariat normal distribution with the estimated parameter mean and variance-covariance matrix. Based on these estimates the expected duration and the effect measures are calculated 500 times, and the empirical standard error is calculated and reported.

Observe that all types of programmes now contribute to reducing the duration of unemployment, if compared to a system without ALMPs - the effect $\Delta_{1}$. Private sector employment subsidies reduce unemployment duration by almost 4 weeks, while 'other programmes' lead to almost 3 weeks' reducation in unemployment duration. Education/training leads to a 2 week reduction, while public sector temporary jobs lead to a one week reduction in unemployment duration. All the estimated effects of this type are statistically significant. If we investigate the 'pure' effect of programme participation 
- the effect $\Delta_{2}$ - we observe, however, that only private sector employment subsidies reduce unemployment duration, and the effect is not even statistically significant. For education/training and for public sector temporary jobs we actually find that the pure programme effect is positive, that is, it increases unemployment duration. Therefore it is very interesting and important to note how the inclusion of the threat effect completely can change the conclusions one would draw from such a study. First, we observe that the presense of ALMPs actually shortens unemployment duration even though actual participation in a programme does not! Second, the reason for this remarkable result is the threat effect, $\Delta_{3}$, which reduces unemployment duration for men by nearly three weeks.

\subsection{Distribution of threat effects}

In Table 3 the threat effect for a person with average characteristics were reported. To get an insight into the importance of the threat effect for a more dispersed group of unemployed we have calculated the threat effect for a subsample consisting of 10,000 randomly selected individuals. Figure 5 shows a histogram of the individual threat effects, that is, for each of these 10,000 individuals we have calculated $\Delta_{3}(\cdot)$ above. 


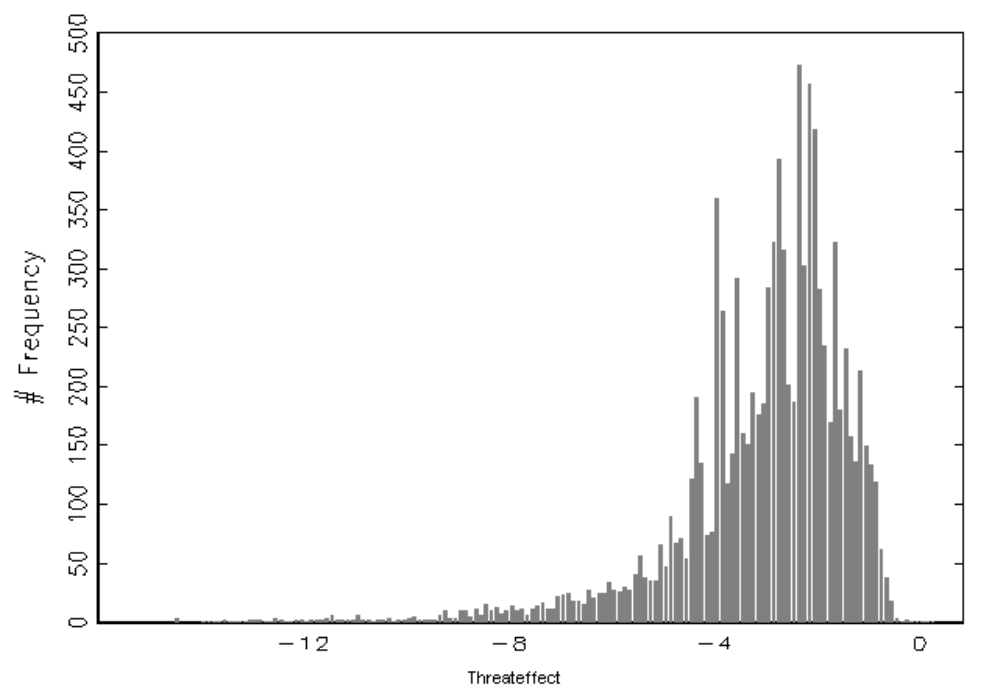

Figure 5: The distribution of threat effects.

The average threat effect is -3 weeks and it ranges from -0.2 to -14 weeks. The figure reveals that for a majority of the individuals the threat effect is quite large, and it therefore plays a significant part in reducing unemployment duration.

\section{Conclusion}

In this study, we have combined two techniques in order to consistently estimate the effect of active labour market policies and, in particular, active labour market policy regimes. Our aim has been to explicitly allow for the threat effect of active labour market policies, that is, to estimate the effect of an active labour market policy regime compared to the counterfactual situation of a passive regime. We have used fairly new Danish data from administrative registers to estimate the parameters of the econometric model. We find a strong and significantly positive threat effect. Note that the threat effect we find is implicit, in the sense that the individual reacts to a perceived risk of programme participation in the future, and not to an actual programme assignment, as 
was the case for the individiuals under the WRPS, see Black et al. (2003). This is the reason we speak of the impact of an active labour market policy regime rather than the effect of an explicit threat.

Taking the threat effect into account, calculations show that an active labour market policy regime shortens unemployment duration, even if actual programme participation does not. This is because of the threat effect, which affects the behaviour of unemployed workers prior to programme participation.

Denmark spends around 1.5\% of GDP annually on ALMPs. This is shown to reduce average unemployment duration by approximately three weeks. In order to determine whether an active labour market policy regime is cost effective, one would in principle have to compare the costs of maintaining such a policy regime to the benefits, which would be the three week reduction in unemployment. However, we would be hesitant to make such a calculation, as we have severely restricted our sample to include only men, only those who have been unemployed for more than four weeks, and only those with no unemployment during the 52 weeks before the current spell of unemployment. Moreover, there may be long-term effect of programme participation on wages and employment duration, which we have not taken into account.

The existence of the threat effect points at a dilemma built into the active labour market policy regime: On the one hand, the focus of the active labour market policy is on upgrading the skills of the work force through education/training and temporary jobs. Moreover, the temporary jobs have an additional function, i.e. to reduce the information problem, which consists of long-term unemployment being a bad signal (of low productivity and/or low work moral) to send to potential employers. Temporary (subsidised) jobs give the employer an opportunity to obtain relevant information at low costs. Temporary jobs also contribute to establishing a social network that may be used as an additional search platform. On the other hand, the ALMPs must have a threatening appearance for the threat effect to work. But programmes can only be frightening if they are either unpleasant, useless, or both. There is an apparent contradiction between the need for effectiveness of the programmes and the need for 
deterrence. Looking at the estimated impacts from this and other papers from the Nordic countries, it would seem that a very active labour market policy regime relies mostly on the threat effect. On the other hand, if policy makers wanted explicitly to achieve a maximal threat effect, there would be several ways of doing that, including the introduction of strict search requirements and severe sanctions for non-complicance, lowering the UI benefits, introducing programmes that are truly cold, wet, hard, and have no skill-enhancing components (e.g. cleaning the beaches) and so on.

A related point is that there are apparently many unemployed workers who are affected by the threat effect. What kind of jobs do these 'programme-threatened' individuals accept compared to the jobs they would have accepted in the absence of a threat? If they lower their reservation wages, they may end up in jobs with lower wages and worse career prospects, and that is not necessarily efficient. On the one hand, transfer incomes are reduced, but on the other hand, perhaps future tax incomes will be lower, too. It would be useful to have a deeper understanding of the consequences of very active labour market policy regimes. This will be on our future research agenda.

\section{References}

[1] Abbring, J. \& G. van den Berg (2003). "The Non-Parametric Identification of Treatment Effects in Duration Models", Econometrica, 71, 1491-1517.

[2] Black, D, J. Smith, M. Berger \& B. Noel (2003): "Is the Threat of Reemployment Services More Effective than the Services Themselves? Evidence from Random Assignment in the UI System", American Economic Review, 93(4), 1313-1327.

[3] Bolvig, I., P. Jensen \& M. Rosholm (2003): "Employment Effects of Active Social Policies", IZA Discussion Paper 738.

[4] Bonnal, L., D. Fougère \& A. Sérandon (1997): "Evaluating the Impact of French Employment Policies on Individual Labour Market Histories", Review of Economic Studies, 64, 683-713. 
[5] Calmfors, L., A. Forslund, M. Hemström (2001): "Does Active Labour Market Policy Work? Lessons From the Swedish Experience", Swedish Economic Policy Review, Vol. 8: 61-124

[6] Geerdsen, L (2002): "Does Labour Market Training Motivate Job Search? A Study of Incentive Effects of Compulsory ALMP in the Danish UI System", Draft, University of Copenhagen.

[7] Gerfin, M. \& M. Lechner (2002): "A Microeconometric Evaluation of the Active Labour Market Policy in Switzerland", Economic Journal, 112 (October), 854-893.

[8] Gritz, R.M. (1993): "The Impact of Training on the Frequency and Duration of Employment", Journal of Econometrics, 57, 21-51.

[9] Hammer, B., M. Rosholm \& M. Svarer (2004): "A Danish Profiling System", Unpublished Manuscript, University of Aarhus.

[10] Heckman, J., R. Lalonde \& J. Smith (1999): "The Economics and Econometrics of ALMP", Handbook of Labor Economics, Vol. 3, North-Holland, Amsterdam.

[11] Jensen, P., M. Rosholm \& M. Svarer (2003): "The Response of Youth Unemployment to Benefits, Incentives, and Sanctions", European Journal of Political Economy, 19, 301-316

[12] Jensen, P. \& N. Westergaard-Nielsen (1990): "Temporary Layoffs", In Hartog, Ridder \& Theeuwes (editors), Panel data and labour market studies. North-Holland, Amsterdam.

[13] Kluwe, J. \& C. Schmidt (2002): "Active Policy Evaluation: Problems, Methods, and Results", Economic Policy, October.

[14] Lalive, R., J. van Ours \& J. Zweimüller (2001): "The Impact of Active Labor Market Programs on the Duration of Unemployment", IEW Working Paper No. 41, University of Zurich. 
[15] Lalive, R., J. van Ours \& J. Zweimüller (2002): "The Effect of Benefit Sanctions on the Duration of Unemployment", IEW Working Paper No. 110, University of Zurich.

[16] Lillard, L. (1993): "Simultaneous Equations for Hazards", Journal of Econometrics, 56, 189-217.

[17] Lubyova, M, \& J. C. van Ours (1999): "Effects of Active Labor Market Programs on the Transition Rate from Unemployment into Regular Jobs in the Slovak Republic", Journal of Comparative Economics, 27, 90-112.

[18] Lancaster, T. (1990): "The Econometric Analysis of Transition Data". Cambridge University Press, Cambridge, UK.

[19] Martin, J. P., D. Grubb (2001). "What Works and for Whom: a Review of OECD Countries' Experiences with Active Labour Market Policies", Swedish Economic Policy Reveiw, 8(2), 9-57.

[20] Ministry of Labour (2000): "Effekten af Aktiveringsindsatsen" (The Effect of Active Labour Market Programmes), The Danish Ministry of Labour.

[21] Munch, J. \& L. Skipper (2003): "The Consequences of ALMP Participation In Denmark", Draft, University of Aarhus.

[22] Narendranathan, W. (1993): "Job Search in a Dynamic Enviroment - An Empirical Analysis", Oxford Economic Papers, 45(1), 1-22.

[23] Richardson, K. \& G. van den Berg (2001): "The Effect of Vacational Employment Training on the Individual Transition Rate from Unemployment to Work", Swedish Economic Policy Reveiw, 8(2), 175-214.

[24] Rosholm, M. \& M. Svarer (2001): "Structurally Dependent Competing Risks", Economics Letters, 73 (2), 169-173. 
[25] Rosholm, M., L. Skipper (2003): "Is Labour Market Training a Curse for the Unemployed? Evidence from a Social Experiment", IZA Discussion Paper 716.

[26] Sianesi, B. (2004): "An Evaluation of the Swedish System of Active Labour Market Programmes in the 1990s", Review of Economics and Statistics, 86(1), 133-155.

[27] Stanley, M., L. Katz \& A. Krueger (1999): "Impacts of Employment and Training Programmes: The American Experience", Draft, Harvard University.

[28] van den Berg, G. (1990). "Nonstationarity in Job Search Theory", Review of Economic Studies, 57, 255-277.

[29] van den Berg, G., B. van der Klaauw \& J. C. van Ours (2004): "Punitive Sanctions and the Transition Rate from Welfare to Work", Journal of Labor Economics, $22(1), 211-241$. 